\title{
Commentary \\ Nitric oxide, leukocytes and microvascular permeability: causality or bystanders?
}

\author{
Balázs Hauser ${ }^{1,2}$, Martin Matejovic ${ }^{3}$ and Peter Radermacher ${ }^{1}$
}

\begin{abstract}
${ }^{1}$ Sektion Anästhesiologische Pathophysiologie und Verfahrensentwicklung, Universitätsklinikum, Parkstrasse 11, 89073 Ulm, Germany
${ }^{2}$ Aneszteziológiai és Intenziv Terápiás Klinika, Semmelweis Egyetem, H-1125 Kietvolgyi, Budapest, Hungary

31. Interni klinika, Karlova univerzita Praha, Lekarska fakulta a Fakultni nemocnice, Allej Svobody 80, 30460 Plzen, Czech Republic
\end{abstract}

Corresponding author: Peter Radermacher, peter.radermacher@uni-ulm.de

Published: 16 January 2008

Critical Care 2008, 12:104 (doi:10.1186/cc6214)

This article is online at http://ccforum.com/content/12/1/104

(c) 2008 BioMed Central Ltd

See related research by Hollenberg et al., http://ccforum.com/content/11/6/R125

\begin{abstract}
Increased microvascular permeability resulting in tissue edema is a hallmark of sepsis-related microcirculatory failure, and leukocyteendothelium interaction is thought to assume major importance in this context. However, the role of nitric oxide (NO) in the interplay of inflammation, leukocyte-endothelium interaction and increased microcirculatory permeability is still a matter of debate. Hollenberg et al. now report, in the previous issue of Critical Care, that neither genetic deletion nor pharmacologic blockade of the inducible isoform of the NO synthase (iNOS) affected the sepsis-related aggravation of leukocyte rolling and adhesion, whereas iNOS inhibition attenuated microvascular permeability. The authors conclude that excess NO resulting from iNOS activation is important in modulating vascular permeability during sepsis, but that this effect is independent of its action on leukocytes.
\end{abstract}

Increased microvascular permeability resulting in tissue edema is a hallmark of sepsis-related microcirculatory failure, and in this context leukocytes are thought to assume major importance. However, the role of nitric oxide (NO) in the interplay of inflammation, leukocyte-endothelium interaction and increased microcirculatory permeability is still a matter of debate. It is well established that $\mathrm{NO}$ has a pivotal role in the regulation of vasomotor tone as well as in host defense and immune function, and abundant literature is available on both its protective and its detrimental properties, which depend on the source of its release (for example, isoenzyme activation), the timing and the amount of its production, and the redox status of the surrounding milieu. In the previous issue of Critical Care, Hollenberg et al. [1] added another piece to this complex puzzle. Using a well-established, clinically relevant murine model of resuscitated, hyperdynamic sepsis resulting from cecal ligation and puncture (CLP) [2], the authors studied the effects of both genetic deletion and pharmacologic blockade of the inducible isoform of the NO synthase (iNOS) on leukocyte adhesion and rolling as well as on microvascular leakage. In this model, the authors had previously shown that iNOS ${ }^{-1-}$ mice presented with improved microvascular catecholamine responsiveness and, ultimately, enhanced survival [2]. As expected, in the present study CLP itself aggravated leukocyte rolling and adhesion. Interestingly, deletion of iNOS did not affect this response, whereas it attenuated microvascular permeability. In sham-operated control mice, iNOS-derived NO inhibited the interaction between leukocytes and endothelial cells (rolling and adhesion), but not microvascular permeability. The authors concluded that excess NO resulting from iNOS activation is important in modulating vascular permeability during sepsis, but that this effect is independent of its action on leukocytes.

How do these findings compare with the available literature on the role of $\mathrm{NO}$ in leukocyte-endothelium interaction and microvascular permeability?

More than a decade ago, Kubes et al. showed that nonselective NO synthase inhibition increased leukocyte adherence [3]. This effect was closely related to oxidative stress resulting from an enhanced production of superoxide radicals [4], thus demonstrating the importance of $\mathrm{NO}$ as an oxygen radical scavenger. In rats with CLP, non-selective NO synthase inhibition also increased leukocyte migration [5]. Activation of iNOS seemed to be responsible for the protective properties of $\mathrm{NO}$, because $\mathrm{iNOS}^{-/-}$mice challenged with lipopolysaccharide presented with a comparably increased accumulation of pulmonary leukocytes [6]. Furthermore, iNOS $^{-/}$caused enhanced pulmonary inflammation after instillation of lipopolysaccharide into the lung [7], whereas wild-type controls and mice lacking endothelial NO synthase $\left(\mathrm{eNOS}^{-/-}\right)$presented with similar less pronounced 
inflammatory responses. Finally, iNOS ${ }^{-/-}$mice subjected to lethal CLP showed even more pronounced leukocyte rolling and adhesion than wild-type controls treated with the nonselective NO synthase blocker aminoguanidine [8]. Because $\mathrm{NO}$ affected only minimally the most important adhesion molecules (P-selectin, E-selectin and vascular cell adhesion molecule-1) regulating leukocyte response, Hickey et al. concluded that iNOS-related changes affecting leukocyte behavior in the microcirculation are due to an altered leukocyte function rather than an altered endothelial function [9].

The picture is far less straightforward with regard to microvascular permeability. Clearly, Kubes and Granger [10] elegantly demonstrated that the non-selective NO blockade markedly increased fluid leakage into the extravascular space. This effect was due not only to increased microvascular hydrostatic pressure but also to increased microvascular permeability [10]. Nevertheless, Paul Kubes also emphasized the 'continuing dilemma of $\mathrm{NO}$ and microvascular permeability' [11] due to the compelling evidence that endogenous NO may either decrease or increase fluid leakage [12]. In fact, even inhaled NO was reported to increase epithelial permeability and alveolar fluid leakage in rats with pneumonia [13], a rather intriguing observation because Benzing et al. [14] had reported decreased transvascular albumin flux in patients with acute lung injury, which was due at least in part to a fall in the pulmonary effective capillary pressure; that is, the microvascular hydrostatic pressure. Differentiating between the constitutive endothelial, and inducible NO synthase isoforms, namely eNOS and iNOS, adds to the complexity: the present data by Hollenberg et al. clearly indicate a major role of iNOS, whereas other authors investigating both $\mathrm{eNOS}^{-/-}$and $\mathrm{iNOS}^{-/-}$animals found that iNOS was associated with protective rather than deleterious properties; in fact, in the present study, NOS $^{-/}$mice challenged with CLP presented with less microvascular leakage, whereas $\mathrm{eNOS}^{-/-}$mice were protected against tissue edema after intrapulmonary instillation of lipopolysaccharide [7], zymosan injection into the paw [15], and injection of platelet-activating factor into the mesentery [16].

Consequently, what do we learn for clinical practice? Or, in other words, shall we say 'No to iNOS' so as to attenuate sepsis-induced tissue edema resulting from microvascular failure? Data from clinically relevant, resuscitated models of both genetic and pharmacologic iNOS inhibition [1,2] clearly favor this approach, and similar conclusions can be drawn from existing reports on large animals [17]. Nevertheless, it must be emphasized that 'a mouse is not a man': in rodents, endogenous NO production is higher by one or two orders of magnitude than in human beings [18]. In addition, it must be noted that up to now clinical data have not supported a direct relation between $\mathrm{NO}$ release and the capillary filtration coefficient, a noninvasive index of microvascular permeability [19]. Consequently, a definite answer is still lacking.

\section{Competing interests}

The authors declare that they have no competing interests.

\section{References}

1. Hollenberg SM, Guglielmi M, Parrillo JE: Discordance between microvascular permeability and leukocyte dynamics in septic inducible nitric oxide synthase deficient mice. Crit Care 2007, 11:R125.

2. Hollenberg SM, Broussard M, Osman J, Parrillo JE: Increased microvascular reactivity and improved mortality in septic mice lacking inducible nitric oxide synthase. Circ Res 2000, 86:774779.

3. Kubes P, Suzuki M, Granger DN: Nitric oxide: an endogenous modulator of leukocyte adhesion. Proc Natl Acad Sci USA 1991, 88:4651-4655.

4. Gaboury J, Woodman RC, Granger DN, Reinhardt P, Kubes P: Nitric oxide prevents leukocyte adherence: role of superoxide. Am J Physiol 1993, 265:H862-H867.

5. Sundrani R, Easington CR, Mattoo A, Parrillo JE, Hollenberg SM: Nitric oxide synthase inhibition increases venular leukocyte rolling and adhesion in septic rats. Crit Care Med 2000, 28: 2898-2903.

6. Hickey MJ, Sharkey KA, Sihota EG, Reinhardt PH, Macmicking JD, Nathan C, Kubes P: Inducible nitric oxide synthase-deficient mice have enhanced leukocyte-endothelium interactions in endotoxemia. FASEB J 1997, 11:955-964.

7. Speyer CL, Neff TA, Warner RL, Guo RF, Sarma JV, Riedemann NC, Murphy ME? Murphy HS, Ward PA: Regulatory effects of iNOS on acute lung inflammatory response in mice. $A m$ J Pathol 2003, 163:2319-2328.

8. Benjamim CF, Silva JS, Fortes ZB, Oliveira MA, Ferreira SH, Cunha FQ: Inhibition of leukocyte rolling by nitric oxide during sepsis leads to reduced migration of active microbicidal neutrophils. Infect Immun 2002, 70:3602-3610.

9. Hickey MJ, Granger DN, Kubes P: Inducible nitric oxide synthase (iNOS) and regulation of leukocyte/endothelial cell inrteractions: studies in iNOS-deficient mice. Acta Physiol Scand 2001, 173:119-126.

10. Kubes $P$, Granger DN: Nitric oxide modulates microvascular permeability. Am J Physiol 1992, 262:H611-H615.

11. Kubes P: Nitric oxide and microvascular permeability: a continuing dilemma. Eur Respir J 1997, 10:4-5.

12. Kubes $P$ : Nitric oxide affects microvascular permeability in the intact and inflamed vasculature. Microcirculation 1995, 2:235244.

13. Ader F, Le Berre R, Lancel S, Faure K, Viget NB, Nowak E, Niviere $\mathrm{R}$, Guery B: Inhaled nitric oxide increases endothelial permeability in Pseudomonas aeruginosa pneumonia. Intensive Care Med 2007, 33:503-510.

14. Benzing A, Bräutigam P, Geiger K, Loop T, Beyer U, Moser E: Inhaled nitric oxide reduces pulmonary transvascular albumin flux in patients with acute lung injury. Anesthesiology 1995, 83: 1153-1161.

15. Bucci M, Roviezzo F, Posadas I, Yu J, Parente L, Sessa WC, Ignarro LJ, Cirino G: Endothelial nitric oxide synthase activation is critical for vascular leakage during acute inflammation in vivo. Proc Natl Acad Sci USA 2005, 102:904-908.

16. Hatakeyama T, Pappas PJ, Hobson RW, Boric HI, Sessa WC, Durán WN: Endothelial nitric oxide synthase regulates microvascular hyperpermeability in vivo. J Physiol 2006, 574: 275-281.

17. Hauser $B$, Bracht $H$, Matejovic M, Radermacher $P$, Venkatesh $B$ : Nitric oxide synthase inhibition in sepsis? Lessons learned from large-animal studies. Anesth Analg 2005, 101:488-498.

18. Reade MC, Young JD: Of mice and men (and rats): implications of species and stimulus differences for the interpretation of studies of nitric oxide in sepsis. Br J Anaesth 2003, 90: 115-118.

19. Dhillon SS, Mahadevan K, Bandi V, Zheng Z, Smith W, Rumbaut RE: Neurophils, nitric oxide, and microvascular permeability in severe sepsis. Chest 2005, 128:1706-1712. 